\title{
A ARTE E A IMAGEM DAS MÁQUINAS
}

Angela Brandão*

\section{Resumo}

Este artigo pretende refletir sobre as relações entre arte e tecnologia, concentrando-se na representação das máquinas pela arte, mas também nas transformações da linguagem artística provocadas por estas relações. Trata-se, especialmente, de uma análise da importância das máquinas na estética futurista e nas obras de Fernand Léger e de sua aluna brasileira, Tarsila do Amaral, observando rapidamente a presença das máquinas na arte do século XIX e em outras manifestações artísticas do século XX, bem como de uma breve reflexão sobre a fotografia e o cinema.

Palavras-chave: arte; tecnologia; futurismo; Fernand Léger; Tarsila do Amaral.

As relações entre arte e técnica não são menos complexas do as que se estabeleceram entre sociedade e tecnologia. A presença das máquinas, desde o séculos XVIII e sobretudo XIX, em contínuo crescimento, passou a marcar a vida dos homens, não somente em seu trabalho, nas fábricas, mas nos momentos de descanso e em vários aspectos do cotidiano. Mais do que isso, as máquinas passaram a exigir uma adaptação do homem aos ritmos, à presença e ao funcionamento maquínico. Pela presença transformadora das máquinas, os homens tiveram que alterar sua sensibilidade, sua percepção da realidade, seu próprio ritmo de trabalho e de existência, suas ações e seu pensamento. Todas essas transformações não poderiam deixar de refletir-se também no campo estético: as mudanças da arte no decorrer do processo de maquinização da sociedade são um claro indício a esse respeito.

* Mestre em História pela Universidade Estadual de Campinas e doutora em História da Arte pela Universidad de Granada. Professora do Departamento Acadêmico de Desenho Industrial da Universidade Tecnológica Federal do Paraná. (brandaoangela@hotmail.com) 
Gostaríamos de refletir, neste texto, especialmente sobre a representação das máquinas, concentrando-nos nas primeiras décadas do século XX.

William Turner (1775-1851), um dos mais criativos pintores de paisagem de seu tempo e preocupado com o registro dos efeitos da luz na atmosfera, foi talvez o primeiro a registrar uma máquina rasgando a paisagem no óleo sobre tela intitulado "Chuva, Vapor e Velocidade", de 1844. Embora Turner não estivesse interessado em registrar a locomotiva, como um tema em si mesmo, a presença da máquina, ali, irrompendo a atmosfera de vapor e chuva, parece indicar que, assim como em seus quadros de naufrágios e tormentas no mar, houvesse uma manifestação do "sublime". O "sublime", como um conceito próprio da estética romântica, constituía um modo de perceber a natureza e, portanto, de registrar a pintura de paisagens. A grandiosidade e o caráter ameaçador da natureza eram parte do sentido de sublime. É curioso como no quadro de Turner, "Chuva, Vapor e Velocidade”, o motivo de manifestação do sublime não está somente no aspecto assustador das forças da natureza, mas ao contrário, a locomotiva parece, não vítima como o navio que naufraga, mas tão asssutadora quanto a paisagem tumultuada (CUZIN e LACLOTTE, 1996, p. 2308-2310).

Para Marc Le Bot (1979), em seu livro "Pintura e Maquinismo", a introdução da realidade industrial no imaginário do século XIX teria se efetuado, no entanto, na obra de Bonhommé. Esse pintor mostrava paisagens rurais transformadas pela industrialização e, no interior das fábricas, as máquinas são apresentadas com detalhes minuciosos, próprios da pintura realista. Adolph von Menzel (1815-1905), por outro lado, utilizou as estruturas metálicas das fábricas, as engrenagens emaranhadas e roldanas, a luz das fornalhas, como um cenário infernal para localizar a força e a angústia dos trabalhadores. O quadro "A Forja”, de 187275 recebeu, por parte do pintor, significativamente, o título explicativo: "Ciclopes Modernos" (KRAUSSE, 2000, p. 67, 126)

Embora a pintura do século XIX, em sua vertente considerada realista, tenha iniciado a representação do trabalho nas fábricas e a presença das máquinas em meio aos trabalhadores, o primeiro movimento artístico, na segunda metade do século XIX, a deixar que as transformações do industrialismo produzissem não apenas mudanças temáticas, mas 
mudanças estéticas, foi o impressionismo. Os impressionistas, ao registrar cenas urbanas noturnas, os cafés e cabarés, indicavam seu encanto pelas luzes elétricas e pelos hábitos modernos. Os trens, as estações, o vapor e a velocidade estavam também presentes na sensibilidade impressionista.

Claude Monet (1840-1926) procurou pintar a grandiosidade das locomotivas e das estações de trens; Constantin Meunier (18311905), pintor e escultor belga, havia tentado fixar a fumaça das fábricas, enobrecendo a figura dos trabalhadores. Mas a velocidade dos trens, a visão de paisagens que passam pela janela em movimento, diante dos olhos de um viajante levado rapidamente, as luzes elétricas, o vapor, estes novos elementos combinados produziram uma nova forma de percepção estética da realidade: os impressionistas criaram uma pintura veloz, lumínica, vaporosa, manchada, que captava o instante. Poderíamos evocar a relação mesma entre a pintura impressionista e as máquinas fotográficas de dimensões mais portáteis, o que resultara em composições espontâneas e capturas de realidades fugazes (REWALD, 1991).

No entanto, foi o futurismo, sobretudo em sua vertente italiana, em torno a Marinetti, a primeira manifestação artística que declarava abertamente a exaltação da técnica e de uma nova beleza maquínica. $\mathrm{O}$ primeiro manifesto futurista assinalava já todos os novos aspectos da vida urbana, na idade do maquinismo, como modificação da sensibilidade artística (LE BOT, 1979).

Os futuristas declaravam em seu manifesto de 1909 que "o esplendor do mundo se enriqueceu com uma nova beleza: a beleza da velocidade”. Propunham, assim, uma nova estética que evocasse o poder das máquinas e a beleza do progresso técnico. "Queremos cantar o homem que conduz o volante". O homem que, por si só, não representava o interesse e a busca deste movimento artístico. Negava-se o humanismo e o antropocentrismo em nome de um novo deus - a técnica - e em nome de um novo homem, o que conduz, o que se adaptou às máquinas (VERDONE, 1994, p. 8386).

O manifesto futurista culminava numa nova concepção de tempo: "O Tempo e o Espaço morreram ontem. Já vivemos no Absoluto, posto que criamos a eterna velocidade onipresente". A velocidade dos meios de 
comunicação e de transporte destruíam as noções tradicionais de tempo e espaço. As distâncias diminuíam. A experiência do trajeto a ser percorrido, a experiência da viagem e da duração, com os trens, os primeiros aviões e automóveis, foram totalmente transformadas. A velocidade ganhou, no discurso futurista, o atributo divino da onipresença (VERDONE, 1994:8386).

Os futuristas procuraram figurar o movimento, representar plasticamente o movimento. Giacomo Balla (1871-1958) se lançou para a observação experimental do movimento, integrando em sua pintura os efeitos cronofotográficos. A invenção do cinematógrafo tinha acostumado ao espectador a seguir o processo de uma fotografia que se põe em movimento: superposição de imagens na retina. No mesmo princípio se baseavam os futuristas para conseguir a ilusão de movimento, deslocando as linhas de um objeto fundamental (linhas de força), assim se reproduzia seu dinamismo. O cubismo tinha feito possível a reprodução simultânea da proximidade/distância, frente/perfil, mas os futuristas dariam um efeito muito mais amplo ao falar de "simultaneidade". Surgia de uma fonte literária e buscava uma expressão plástica (FABRIS, 1987).

A estética futurista, com sua perspectiva de valorização exagerada do poder das máquinas, chegou a proposições extremamente agressivas, como a exaltação da guerra, enquanto espetáculo dos novos aparatos bélicos. No manifesto de Marinetti, sobre a guerra da Etiópia, chegou a escrever: "Há vinte e sete anos estamos nos levantando, os futuristas, contra a que se considere a guerra antiestética... por isso mesmo afirmamos: a guerra é bela, porque graças às máscaras de gás, ao terrífico megafone, aos lançachamas e aos tanques, inaugura-se a soberania do homem sobre a máquina subjugada. A máquina é bela, porque inaugura o sonho da metalização do corpo humano (...)" (VERDONE, 1994, p. 86-88).

O futurismo foi gerado pela necessidade de encontrar uma expressão cultural para os tempos de industrialização. O erro foi considerar que 0 progresso da técnica eqüivalia ao progresso do homem. Para o futurismo, a beleza da velocidade era a nova beleza: "um automóvel de corrida com seu capô ornamentado com grossos tubos parecidos com serpentes de hálito explosivo... um automóvel que ruge é mais bonito que a Batalha de 
Samotrácia." Decretam a morte da mitologia passada em nome de um novo mito: o automóvel. O futurismo queria a adequação da arte ao novo ritmo da vida. $\mathrm{O}$ estilo deveria tornar-se rápido, impetuoso, turbilhonante como a vida moderna. $\mathrm{O}$ barulho da cidade era um dos temas privilegiado do futurismo italiano. Os meios de transporte modernos inspiram construções sincopadas de imagens fragmentadas que representam a acumulação incoerente dos estímulos sobre os olhos de um observador em rápido deslocamento. Tratava-se, muitas vezes, de uma espécie de colagem, cujos componentes estariam acionados no tempo. Lia-se no manifesto de 1910: "o ônibus se lança sobre as casas, que por sua vez se precipitam sobre o ônibus e se fundem com ele.” (FABRIS, 1987; VERDONE, 1994, p. 86$88)$.

Evocando as cenas urbanas, Eugenio D'ors falará de uma embriaguez descritiva diante da confusão urbana; Duchamp, de um "impressionismo do mundo mecânico". O futurismo queria fixar imagens instantâneas que se inscrevessem sobre a retina, que no quadro se tornassem ritmo e textura (BOZZOLA e TISDAL, 1993).

Um dos ideais dos futuristas era, portanto, o caos. Representaram um turbilhão vertiginoso de emoções: sons, cheiros, cores, formas, tudo deveria ser pintado. Havia, para eles, sons e ruídos e cheiros côncavos e convexos, triangulares. Do ponto de vista das cores, havia sons, ruídos e cheiros amarelos, roxos, verdes, anis, azul celeste e violáceos. O colorido costuma ser, precisamente, o aspecto mais forte da pintura futurista (BOZZOLA e TISDAL, 1993).

$\mathrm{O}$ interesse dos futuristas sobre os ruídos se transportou para 0 campo da música. Os músicos publicaram também um manifesto futurista, contra a tirania cronométrica do ritmo. Luigi Russolo (1885-1947), pintor e músico italiano, publicou em 1913 o manifesto "A arte dos ruídos" e criou o Intonarumori (aparelho de ruído), que produzia todo tipo de sons, incorporando à arte o alvoroço da rua e o barulho das máquinas. Experiências que mais tarde influenciariam à música concreta (BOZZOLA e TISDAL, 1997).

A partir de 1928, se produziu na Itália um futurismo de tendência mística e idealista. O manifesto da Aeropintura foi assinado em 1929 pelos 
artistas Balla, Prampolini, Depero. A aeropintura consistia numa visão dinâmica a partir do alto, nova e imprevisível, das máquinas voadoras, também marcada pela simultaneidade de situações. $\mathrm{O}$ vôo mostrava, para eles, uma nova realidade diferente da perspectiva terrestre. Esta nova realidade, permitida pela aeronave, não tinha ponto fixo. Pintar de cima pressupunha 0 abandono dos detalhes. Os aeropintores buscavam, portanto, uma espiritualidade extraterrestre (VERDONE, 1994, p. 65-68).

Fernand Léger (1881-1955), um dos mais criativos intérpretes da linguagem cubista, tratou do dinamismo sem a sobreposição e a simultaneidade dos futuristas. Para o pintor francês, o dinamismo era produzido pelo contraste entre as cores (branco - preto - vermelho), pelo contraste entre o plano e o volumétrico, pelo contraste entre o curvo e o retilíneo. A imagem plana era apreendida rapidamente (como um cartaz), o volume, a modelagem ralentiza os olhos (LÉGER, 1989, p. 49-75)

Léger construiu a visão da bondade da civilização e um entusiasmo com a modernização. Situou-se, assim, a meio caminho entre o cubismo e o futurismo. Rejeitou qualquer carga literária na obra de arte. O quadro era, para ele, um objeto autônomo em relação à natureza e regido, portanto, por suas próprias leis. Buscava, assim, o modo próprio de representação da pintura, que fugia à perspectiva renascimental (LÉGER, 1989).

Sua devoção ao mundo das máquinas diferia da dos futuristas, pois não investigava o movimento ou o ruído maquínico, mas estava preocupado com a representação plástica das máquinas. Não se tratava de registrar o movimento e o som, de imprimir sensações "impossíveis" à pintura. O quadro não queria ser outra coisa que não o próprio quadro, em sua redundante bidimensionalidade.

Mesmo na natureza morta, os objetos pareciam tratados como objetos mecânicos. Opunha, no entanto, em alguns casos, a força dos elementos mecânicos à suavidade dos elementos naturais. Aberto à vida moderna, Léger tomou consciência da beleza da máquina antes da guerra de 1914, visitando, com Brancusi e Duchamp, uma exposição de aviação. Para ele era preciso saber utilizar os elementos mecânicos na pintura (LAUGIER e RICHET, s.d.). 
Ao contrário do futurismo, depois da Primeira Guerra Mundial, a presença das máquinas se tornou ainda mais forte na pintura légeriana. Durante a Guerra, Léger ampliou sua confiança na beleza plástica das máquinas. Suas figuras passam a se aproximar da idéia dos soldados, feitos com a mesma matéria dos canhões, que tanto atraíam Léger. Os corpos femininos tendiam a ser tratados com aspecto mecânico também, desmontáveis, sem expressão. Buscava rostos inexpressivos que se tornariam sua marca (LAUGIER e RICHET, s.d.).

As máquinas de Léger não são reais, mas inventadas. O elemento mecânico era para ele um meio de conseguir uma sensação de força e potência. Em 1920, Léger conheceu Le Corbusier, o importante arquiteto suíço, e se influenciou por seu purismo: os objetos cotidianos passaram a ser tratados com um rigor pelo qual foi suprimido todo elemento supérfluo, inclusive a figura humana, porque evocava sentimentos. O elemento industrial era agora elevado à dignidade de um monumento arquitetônico (LAUGIER e RICHET, s.d.).

Léger foi o criador de uma nova inconografia para a era industrial, para a era dos objetos industriais. Os utensílios apareciam, em seus quadros, polidos e metalizados. Não se tratava, muitas vezes, da representação de uma máquina real, mas de um objeto autônomo. A série dos elementos mecânicos, pintados em 1924, se relacionava estreitamente com os motores de carros, com engrenagens de bielas e pistão. Léger servia-se da máquina, em suas palavras, para brutalizar a tradição (LÉGER, 1989). Mas não se tratava de uma arte desumana e sim da exaltação da força, da potência do próprio corpo humano, capaz de dominar a natureza através da técnica.

É corrente que se entenda, da mesma forma, a obra de Tarsila do Amaral (1890-1873), pintora brasileira e aluna de Léger, como um elogio à modernização, como uma homenagem aos trens, automóveis, à eletrificação ou aos arranha-céus. Na exposição individual da pintora, em 1929 no Rio de Janeiro, um dos textos publicados no catálogo procurava afirmá-la como "mulher dinâmica do mundo super-industrializado", "poetiza de amperagens, que marcam o ritmo das forças, que agitam a máquina moderna: a sinfonista das cores e da música que chegavam aos 
nossos ouvidos, e que, só neste século, começaram a ser interpretadas" (CHATEAUBRIAND, 1929, p. 30).

Estas eram as idéias de Assis Chateaubriand, publicadas por primeira vez ainda em 1925 e retomadas aqui, nesta coletânea de artigos, para o catálogo de 29 . O jornalista continuava, mais adiante, afirmando a sintonia entre a arte de Tarsila e a modernização.

Tarsila do Amaral sente apaixonadamente o Brasil antigo, mas sobretudo, ela vibra é diante da cidade moderna, com os arranha-céus, que desafiam as nuvens esfarrapadas, as usinas barulhentas, os Stadiuns ensurdecedores, os rings, onde os boxeurs se esmurram, fazendo sangue viril, ardente e generoso, as pontes metálicas, os arcos elétricos, os trens de ferro resfolegantes, que passam, os geradores que acumulam forças misteriosas, para distribuí-las depois a mãos largas, sob a forma de luz e de energia, aos homens transeuntes; o espetáculo em suma, o knock-out, dado pelo frenesi delirante do pulso mecanizado ao drama clorótico da vida contemplativa.

Ela procura na sua arte oferecer uma representação plástica da época em que foi chamada a agir. O São Paulo novo, que está crescendo, a força do industrialismo triunfante era o assunto à espera de pintor. Tarsila do Amaral está sendo a artista da civilização mecânica, dos homens máquinas, em que vamos entrando em São Paulo.(...)

É o século XX o iniciador da reação suspirada; e os instrumentos do combate, quem os forja, os aperfeiçoa, os estandardiza [sic], é a América brutal, metálica, semibárbara, criadora ou valorizadora dos arranha-céus, da radiotelefonia, do fox-trot, da vontade de poder, da vida intensa, do petróleo, dos músculos, do boxe, da máquina de escrever e contar, a América, mãe desta civilização de arte, inquieta, veloz, fulminante, que ulula na trepidação de um jazz-band, no frenesi de uma especulação de bolsa, na 
precipitação vertiginosa de um side-car, e na opulência dos jogos de luz de um arco-elétrico.

Tarsila do Amaral é a jovem força natural da energia brasileira, que se dispôs a interpretar a nova mecânica artística da hum anidade.(CHATEAUBRIAND, 1929:33-35)

As palavras, de um futurismo entusiástico, de Chateaubriand aproximam a obra de Tarsila da evolução maquínica e do frenesi pelo progresso técnico. Ela é, neste entendimento, a pintora da contemporaneidade, a artista que incorpora em sua arte a modernização de São Paulo dos anos vinte, estetizando-a. É curioso como a agressividade da fala de Assis Chateubriand pouco tem a ver com a serenidade dos quadros de Tarsila, mesmo aqueles que retratam, justamente, os sintomas de São Paulo urbana e moderna.

De qualquer maneira, não havia dúvidas de que a obra da pintora se combinava, naqueles anos, com a expressão da industrialização e da aceleração dos ritmos urbanos. Blaise Cendrars, poeta franco-suiço, escreveu nos poemas de introdução ao catálogo da exposição de Tarsila, realizada em Paris: "A alegria de viver e de ganhar dinheiro se exprime pela voz das buzinas e dos canos de escapamentos abertos". Em seu poema, São Paulo era o lugar onde não havia mais nenhuma tradição e as poucas "velhas casas portuguesas que restavam eram faianças azuis". A extinção do passado, em nome da efervescência modernizante, ganhava contornos estéticos na poesia de Cendrars, assim com na pintura de Tarsila. O silêncio e as velhas casas eram substituídos pelo ruído das buzinas e fábricas e pela especulação imobiliária que construía "dez casas por hora" (CENDRARS, 1929, p. 52-54).

A compreensão da obra de Tarsila como expressão da modernidade percorre, de modo unânime, as leituras que se fizeram sobre ela e sobre sua filiação à estética de Léger. Parece não restar dúvidas para Fernando de Morais: "o melhor de Tarsila está nos seus trabalhos da fase Pau-Brasil porque neles Tarsila se mostra plasticamente mais rigorosa, sua pintura tem um caráter claramente estrutural, refletindo portanto, sua descendência cubista, especialmente seu aprendizado com Fernand Léger (1989) na tentativa de captação da nossa realidade urbana - o semáforo, o luminoso, 
o poste, o automóvel, a vida dinâmica da grande cidade, ainda que tocada por uma certa nostalgia do mundo rural" (MORAIS, 1973). Apesar deste importante detalhe na fala de Fernando Morais sobre a nostalgia, Tarsila continua sendo, principalmente, a pintora da modernização urbana.

Carlos Zílio reafirmava também esta ligação entre Léger, Tarsila e a estetização das paisagens industriais. Dizia: "A atenção de Tarsila voltase principalmente para a pintura de Léger, talvez pelo fato de ser ela (...) a que irá se dedicar mais intencionalmente a incorporar a dinâmica das transformações que a industrialização trazia à vida brasileira”. E também:

o que ela [Tarsila] irá absorver de determinante no sistema de Léger é a utilização do modelo da máquina. (...) adotando a linguagem da máquina (assim como Oswald de Andrade se utiliza da linguagem telegráfica) com um desejo de atualização, no sentido de situar a percepção do Brasil a partir da ótica aberta pela industrialização. A máquina no seu trabalho não será apenas uma referência ao presente, será igualmente a tentativa de apreender o universo simbólico brasileiro, por um olhar compatível com seus aspectos mais contemporâneos (ZÍlLIO, 1982, p. 79-82).

Acrescentar-se-ia, pouco depois, que a ligação da obra de Tarsila com Léger "se fará, assim, não na utilização de um espaço propriamente cubista, mas através do grafismo usado para descrever o parque industrial nascente. Pontes, trilhos de ferro, a própria torre Eiffel no carnaval da Madureira de 24 (...) utilização dos vários recursos gráficos para retratar o mecânico que nos seus limites ásperos e linhas retas contrasta com as formas arredondadas e femininas da terra brasileira (...)" (GUINLE, 1983).

Estas idéias se repetiriam ainda, com outras palavras, no catálogo para a exposição do Museu de Arte de Indianápolis. Neste texto, Tarsila, como aluna de Léger, teria respondido ao ritmo e inovações da moderna cidade industrial, tomando como ideal a perfeição das máquinas. "A inclinação pela estética tecnológica urbana colheu frutos imediatos em seu retorno a São Paulo em uma série de trabalhos retratando estações de 
trem, construções de ferro, bombas de gasolina, sinais elétricos e prédios de apartamentos." (HOLLIDAY, 1987, p. 68).

Não é preciso insistir mais. Parece suficientemente claro que a obra de Tarsila se tornou especialmente reconhecida por seu esforço em estetizar a paisagem moderna e, através dos ensinamentos de Léger, em dedicar-se a pintar São Paulo que se modernizava. Era preciso incluir os elementos de modernização nas vistas urbanas. Não havia maneira de fugir dos fios elétricos, dos postes de luz e das estradas de ferro ao registrar as paisagens. Era preciso incluí-los, estetizando-os.

Estas questões não se referem apenas à pintura de Tarsila, mas também a seus desenhos. Não se quer afirmar que haja uma compartimentação na obra da artista no sentido de que tivesse aplicado seus trabalhos em pintura ao tema da cidade modernizada e que tivesse reservado a seus desenhos o tema das cidades históricas. Não é este o ponto. Dois únicos exemplos são suficientes para se perceber que, através do desenho, a artista também se interessava em registrar cenas urbanas com indícios de modernização. São Paulo, um desenho de 1924, registra um aspecto da cidade, com seus edifícios elevados, em construção, com seu bonde e luz elétrica, com seus letreiros, como um cenário desabitado. Cidade com bondinho mostra, em fios de nanquim, a paisagem moderna abreviada em ideograma.

Em contraposição à vanguarda futurista e às propostas de Léger e Tarsila, o dadaísmo passara a apresentar as máquinas de modo desconcertante e sarcástico. Em seus desenhos, por exemplo, Francis Picabia (1879-1953), havia criado composições mecânicas entre 1917 e 1919, como paródias elegantemente sarcásticas de cópias heliográficas convencionais, desenhos de máquinas que não poderiam funcionar de modo algum. Dedicou uma delas, ironicamente, à memória de Leonardo da Vinci (LUCIE-SMITH, 1994, p. 181-183)

Mesmo o artista dadaísta, Marcel Duchamp (1887-1968), havia criado máquinas e projetos de máquinas sem razão de ser, como um triturador de chocolates, em 1914, um óleo e fios sobre tela, hoje no Museu de Arte da Filadélfia. Três cilindros impedidos uns pelos outros de girar. Havia, em Duchamp, a preocupação com a transição, a mudança, o movimento. Sua primeira "máquina”, um moinho de café, de 1911, já 
mostrava este aspecto desajeitado e de impossibilidade ou inutilidade do funcionamento. (BÉHAR e CARASSOU, 1990).

Na exposição de tecnologia da aviação, ao lado de Léger, Duchamp teria dito a Brancusi: "A pintura está condenada, quem conseguirá fazer uma coisa melhor que uma hélice?”. Esta frase ilustra o dilema visual do artista quando confrontado com as realizações da idade industrial e sua introdução na vida de todos os dias. Os quadros a óleo tinham se tornado história, para Duchamp. Mais tarde, ele realizaria suas chapas rotativas de vidro (ótica de precisão), de 1920, aparelho em que cinco chapas de vidro pintadas foram fixadas em um eixo metálico, ao rodar se pareciam com círculos. Os primeiros discos de papel pintados com tinta e lápis, em espirais, aparecem em 1923. Resultariam no que ele chamou de "rotorelevos”, depois de ter pesquisado o movimento nas três dimensões. Estes grafismos sobre discos confundem outra vez pintura e escultura, dando a sensação de relevo quando colocados em movimento, através de recursos de ilusão de ótica (HUGNET, 1957; RICHTER, 1993; RUBIN, 1985).

Por outro caminho, se poderiam perceber as relações entre arte e técnica em torno da fotografia e do cinema. A fotografia abre outro capítulo nas discussões sobre estética e tecnologia. Experimento que surgira no início do século XIX, com a intenção, entre outras, de captar um instante, um momento da realidade, marcaria com isso profundamente a pintura impressionista. Parece certo que as noções de representação da realidade que vigoravam desde o Renascimento estavam relacionadas com a percepção científica da realidade: a perspectiva, a anatomia. O desenho era, ao mesmo tempo, um procedimento artístico e um meio de conhecimento científico. No entanto, as representações artísticas a partir da fotografia e de sua influência sobre a pintura têm relações com uma nova forma de conhecimento científico, em que a mão e os instrumentos manuais são substituídos por um aparelho.

Ainda que o conceito da câmara escura fosse conhecido desde à Antigüidade, foi com as experiências do francês Joseph Nicéphore Niepce (1765-1833) que, em suas pesquisas para aperfeiçoar a litografia, chegou à primeira técnica, a heliografia, (escrita com o sol) para obter imagens a partir de placas de prata ou estanho prateado que serviam como matriz 
para a prensa comum. Utilizando-se de uma câmara escura, fixava imagens diretamente de paisagens tomadas da janela de seu estúdio. Em 1816, conseguiu a primeira imagem fotográfica obtida através da câmara escura. Em 1826, realizou a mais antiga fotografia permanente conhecida. O problema da fixação foi resolvido por Niepce, utilizando como substância foto sensível não o cloreto de prata, mas o betume da Judéia. As primeiras experiências exigiam um tempo de exposição muito grande - cerca de 10 horas - gerando imagens inconcebíveis e fantásticas (ZANNIER, 1990:, p. 513-514).

Niepce passou a colaborar com um produtor teatral e pintor de dioramas Luis-Jacques Mandé Daguerre (1789-1851), que utilizava a câmara escura para desenhos de paisagens de dioramas. Daguerre encontrou uma forma de fixar a imagem da câmara obscura, em 1833, sem utilizar o betume, criando uma imagem positiva sobre placa de cobre folheada de prata. Em 1835, descobriu o fenômeno da imagem latente. Com curta exposição de tempo a imagem se fixava sobre a placa, revelandose em seguida com uso de outras substâncias de fixação e revelação. Em 1939, o invento foi oficialmente anunciado num encontro científico. Cada imagem era uma obra única, já que não havia negativo (ZANNIER, 1990, p. 514).

A fotografia nasceu, entre outras experiências, sintomaticamente, do esforço de um litógrafo e de um pintor, artistas antes que cientistas. Foi criada por razões estéticas, antes que científicas. Os pioneiros da fotografia adotaram a divisão temática da pintura: paisagem, retrato, natureza morta, história. As paisagens fotográficas absorveram o sentido simbólico e sentimental que a pintura lhe atribuía desde o século XVIII. Muitas fotos se inspiraram na pintura impressionista. $\mathrm{O}$ estatuto de arte para a fotografia foi constante afirmação por parte dos fotógrafos, até o ponto em que se pôde falar, no século XX, em fotografia abstrata (ZANNIER, 1990, p. 520-529).

Poderia parecer anacrônico discutir ainda a essência científica ou artística da fotografia. Se parece certo que nem toda fotografia é arte, uma das possibilidades, talvez a primeira e mais importante das possibilidades de aplicação dessa técnica teria sido, sem dúvida, estética. 
Da mesma maneira, o cinema se insere numa discussão como essa. Enquanto técnica, o cinema resultou de uma antiga busca artística de registrar o movimento. Assim, nasceu do cruzamento de três fenômenos: o desenvolvimento da fotografia, o estudo da persistência retiniana e o desenvolvimento da projeção de imagens. Surgiu numa fusão entre experiência científica e espetáculo público. Desenvolveu-se como um saber artístico, como técnica adequada para produzir e traduzir proposições estéticas.

Se o cinema e a fotografia constituem técnicas que se aplicaram e revestiram de caráter artístico, e que nasceram por intenções artísticas, de um lado, a arte moderna e contemporânea foi aproximando-se, em muitas de suas manifestações, da tecnologia.

A partir dos anos 1960 e 1970, as experiências das chamadas arte ótica e arte cinética buscaram efeitos de luzes e movimentos com a aplicação artística de conceitos e inveções científicas, como a holografia e a informática. Buscou-se, nesses movimentos, uma espécie de harmonia mecanicista, chegando a ser quase una arte produzida por máquinas, ou que parecesse produzida por máquinas.

Para refletir sobre um exemplo, de tradição dadaísta, Jean Tinguely (1925-) produziu objetos de arte cinética, construindo desajeitados mecanismos. Suas máquinas apenas funcionam, nada mais, gemem, trepidam como num "desfuncionamento". Têm sido qualificadas, por isso, como "pseudomáquinas", porque se movem sem objetivo, parodiando a deselegância das máquinas e dos homens que lidam com elas (LUCIESMITH, 1994, p. 181-183).

Foi também desde os anos 1960 e 1970 que se tentaram produzir novas concepções de arte a partir do diálogo com elementos tecnológicos. $\mathrm{Na}$ chamada video-arte, a tela da televisão, projetando imagens com mensagem estética, é levada às galerias de arte e museus, combinada a outros elementos plásticos e outras linguagens. Em seguida, abririam-se os caminhos para os procedimentos artísticos com o uso dos computadores. Porém, todas essas coisas são muito complexas e caberiam em outro artigo. 
Com esses poucos exemplos, nesse breve percurso por alguns pontos de relação entre a arte e a tecnologia, observamos, de um lado, a intenção de transformar a aparente objetividade do mundo das máquinas em experiência estética, em transmitir, por meio do tema das máquinas, uma mensagem artística, às vezes embelezando-as e humanizando-as, às vezes satirizando e embrutecendo os objetos maquínicos. Por outro lado, a tecnologia industrial e pós-industrial representou um dos fatores de transformação da linguagem artística mesma, desde o século XIX.

Longe de esgotar o tema, propusemos que arte e tencologia não são mundos que se mantiveram separados na experiência humana. Desde seu nascimento, as inovações tecnológicas foram vistas como tema ou como meio para a manifestação artística, muitas vezes a meio caminho entre a ciência e a estética.

\section{REFERÊNCIAS}

ARGAN, Giulio Carlo. Arte Moderna. São Paulo: Companhia das Letras, 1998.

BÉHAR, Henri e CARASSOU, Michel. Dada: histoire d'une subversion. Paris: Fayard, 1990.

BOZZOLLA, Angelo e TISDALL, Caroline. Futurism. New York: Thames and Hudson, 1993.

CENDRARS, Blaise. São Paulo. Poema que prefaciou o catálogo da exposição de tarsila [sic] em Paris [sic]. Citado no Catálogo da Exposição Individual, 1929.

CHATEAUBRIAND, Assis. Como São Paulo está cultivando a arte moderna. O Jornal, 1925. In Catálogo da Exposição Individual. Rio de Janeiro, 1929.

CUZIN, J.P. e LACLOTTE, M. Dictionnaire de la Peinture. Paris: Larousse, 1996.

FABRIS, Annateresa. Futurismo: uma poética da modernidade. Estudos. São Paulo: Perspectiva, 1987. 
revista tecnologia e sociedade

GUINLE, Jorge. Tarsila: postais do modernismo. Folhetin, Folha de São Paulo, 16 jan. 1983.

HOLLIDAY, T. Day. Art of the Fantastic. Latin America (1920-1970). Indianapolis Museum of Art, 1987.

HUGNET, Georges. L'Aventure Dada (1916-1922). Paris: Galerie de l'Insitut, 1957.

KRAUSSE, Anna-Carola. História da Pintura: do Renascimento aos nossos dias. Lisboa:Könemann, 2000.

LAUGIER, Claude RICHET, Michèle. Léger: oeuvres de Fernand Léger (1881-1955). Col. du Musée National d'Art Moderne. Paris: Centre George Pompidou, s.d.

LE BOT, Marc. Pintura y Maquinismo. Madrid: Ensayos Arte y Catedra, 1979 .

LEGER, Fernand. Funções da Pintura. São Paulo: Nobel, 1989

LUCIE-SMITH, Edward. Movimientos Artísticos desde 1945. Madrid: Destino, 1994.

MICHELI, Mario de. As Vanguardas Artísticas. São Paulo: Martins Fontes, 1991.

MORAIS, Fernando. Tarsila: pau-brasil, antropofagia, social. Diário de Notícias, 20 jan.1973.

RICHTER, Hans. Dadá: Arte e Antiarte. São Paulo: Martins Fontes, 1993.

RUBIN, William S. Dada, Surrealism and Their Heritage. New York: The Museum of Modern Art, 1985.

VERDONE, Mário. Il Futurismo. Il Sapere. Roma: Tascabili, 1994.

ZANNIER, Italo. L'histoire de la photographie. In SGARBI, V. org. Histoire uiverselle del'art. Toledo: Solar, 1990.

ZÍLIO, Carlos. A querela do Brasil. Rio de Janeiro: Funarte, 1982. 